\title{
Evaluation of PAC with Nanoclay as drilling mud
}

\author{
Sahar KAFASHI ${ }^{1, *}$, Gholamreza KARIMI ${ }^{1}$, Mohamadreza RASAEI ${ }^{2}$ \\ ${ }^{1}$ School of Mining, Imam Khomeini International University, Qazvin, Iran \\ ${ }^{2}$ Institute of Petroleum Engineering, University of Tehran, Tehran, Iran
}

\begin{abstract}
Nine different formulations were built and subsequently their rheological properties were measured according to American Petroleum Institute (API). Porous media model was designed by Corel DRAW (Corel Corporation of Ottawa, Canada)computer software and applied on the glass. Using this kind of micro-models enable us to design the porous media with real dimensions. Statistical analyses showed that 75\%wt of nanoclay suspension and Poly anionic cellulose could successfully improve the rheological properties. The existence of nanoclay in the suspension could significantly compensate viscosity reduction up to two times by increasing shear rate.
\end{abstract}

Keywords: Nano clay, poly anionic cellulose, glass micro-model, Rheological properties.

\section{Introduction}

Drilling fluids (commonly prepared as suspensions of bentonite in water) are crucial to not only oil and gas industry, but also geothermal drilling. In addition to their role in facilitating hole cleaning and enhancing lubricity and wellbore stability, such fluids are expected to prevent damage by forming a mud cake on the wellbore Fluid invasion into productive zones has been widely recognized as detrimental to well productivity.

Invasion of fluids to productive regions can exert negative effects on well productivity. Since the invasion of filtrate and particles can result in irreversible formation damage and decreased permeability, the mud cake needs to be formed as fast as possible to prevent the damage caused by solid particles and cuttings [1][2][3][4][5].

Considering their capability to modify mud viscosity and minimize fluid loss within the formation, bentonites are widely administered as supplements to drilling fluids [6][7][8][9][10][11]. Given the advent of nanotechnology in this field and swelling nature of clay nanoparticles in the drilling fluid, which is considered an effective factor for bridging and a firm obstacle to the invasion of drilling fluid into the porous medium, it could be concluded that these materials would cause quick formation of inner filter cake. The present study used a Polyanionic cellulose (PAC) polymer to improve the rheological properties of the drilling mud.

\footnotetext{
* Corresponding Author
} 


\section{Experimental}

\subsection{Material and instruments}

Nano-particles of clay was supplied from Faragostaran Novin company in the size ranging from 1 to 2nm, X-ray diffraction (Philips PW 1040 model), Infrared (IR) (Jasco Model 5300 FT/IR spectrophotometer) and Differential Thermal Analysis (DTA) (Rigaku)techniques were used to determine the clay mineral types. The sample has the chemical composition (wt.\%) $\mathrm{SiO}_{2} 50.95$, $\mathrm{Al}_{2} \mathrm{O}_{3}$ 19.60, $\mathrm{Fe}_{2} \mathrm{O}_{3}$ 5.62, $\mathrm{CaO}$ 1.97, $\mathrm{CaO} 1.97, \mathrm{Na}_{2} \mathrm{O} 3.36, \mathrm{MgO} 3.29, \mathrm{~K}_{2} \mathrm{O} 0.86$ and $\mathrm{TiO}_{2}$ 0.62,LOI 15.45. [12][13][14]. Na-Bentonite (B) was also prepared to achieve a particle size of $75 \mu \mathrm{m}$.

\subsection{Mud Formulation}

patches were prepared by adding either 10.5 and $\mathbf{1 7 . 5} \mathrm{g}$ bentonite and $0.87 \mathrm{~g}(0.25 \% \mathrm{wt})$, $2.62 \mathrm{~g}(0.75 \% \mathrm{wt})$ Nanoclay to $350 \mathrm{ml}$ water and mixed for a specific time in a mixer( EUROSTAR digital IKA-WERKE, Germany), and then labelled as B5N0.25,B5N0.75,B3N0.25,B3N0.75.

\subsubsection{Preparation of the drilling fluid with NaB-Nano-PAC}

The above-mentioned patches were mixed with $1.05 \mathrm{~g}$ of poly anionic cellulose for $30 \mathrm{~min}$ in a mixer and then labeled as B5N0.25pac, B3N0.25Pac, B5N0.75Pac, B3N0.75Pac respectively.

\section{Results and discussion}

\subsection{Rheological properties}

\subsubsection{Time test}

In order to determine mud stability, Viscosity vs. time Graph were plotted at constant shear rate $(0.1$ $\mathrm{s}-1)$ and temperature $\left(120^{\circ} \mathrm{F}\right)$. As Figure1 shows, adding nano clay into the suspension, resulted in favorable behavior, i.e. At first, fluid viscosity was increased by time passing which indicate beginning of formation of bridging agents. However, in low concentration of nano, viscosity was decreased, this phenomena is due to lubricating characterize of nano clays in low quantity (B3N0.25,B5N0.25). A sharp drop in viscosity was observed in case of bentonite suspension(B5). While, mixing the polymer with the bentonite dispersion (B3PAC) increased viscosity, no steady state was detected. Since two phases of sharp reduction in viscosity were noticed in case of B5PAC, adding only polymer to the mud could not yield the desirable properties.

The simultaneous addition of polymer and nanoclay into the base mud slightly increased the viscosity and time stability. (B5N0.75Pac,B5N0.25pac). 


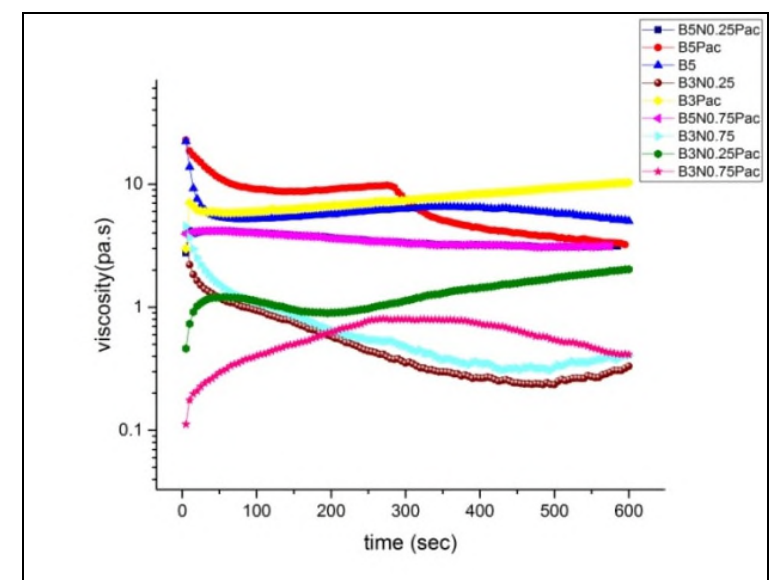

Fig.1: Viscosity vs. time curves of the drilling fluids at $120^{\circ} \mathrm{F}$

\subsubsection{Flow test}

Figure 2 demonstrates changes in viscosity by increasing shear rate. According to the produced curves, the formulations containing Nano clay showed less viscosity drop which means more stability. In fact, at a shear rate of $100 \mathrm{~s}^{-1}$, viscosity reduction of B3N0.75 was about two times lower than that of the base mud (B5). Base fluid (B5) showed the minimum stability . Although B3PAC first showed an increase in viscosity by increasing shear rate, a significant reduction in its viscosity was observed after a short time. Therefore, adding PAC alone could not improve the rheological properties of the mud.

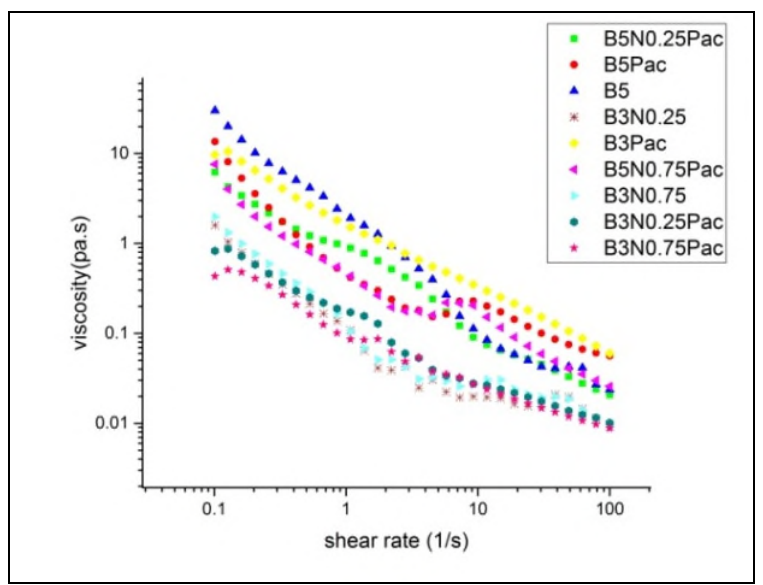

Fig.2: Flow curves of the drilling fluids at $120^{\circ} \mathrm{F}$

\subsection{Mud injection}

Mud injection test was carried out by entering the prepared mud slurry into the syringe of a Nexus 6000 syringe pump system (Chemyx, USA).The fluid penetration test at $1 \mathrm{ml} / \mathrm{h}$ injection rates lasted for 30 minutes. As seen in figure 3, B5N0.75PAC had minimum filtrate penetration into the micromodel. Obviously, lower filtrate penetration depths will be associated with less formation damage. The base mud (B5) caused maximum formation damage during the very first minutes and the filtrate penetrated deeply into the porous media. 


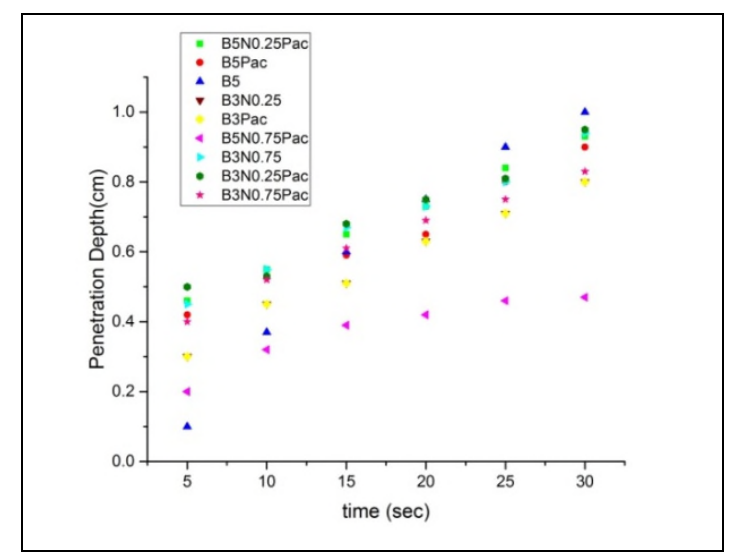

Fig.3: Penetration depth curves of drilling fluids at $1 \mathrm{ml} / \mathrm{h}$

Figure 4 shows the wellbore of the main channel when the cake had not yet formed. Consequently, almost all oil is driven out of the formation. This figure indicates the necessity of creating the filter cake to decrease fluid loss. The following figure depicts the injection of B3N0.25 into the micromodel. As mentioned earlier, low concentration nanoclays are highly lubricating and they can reduce the level of viscosity.

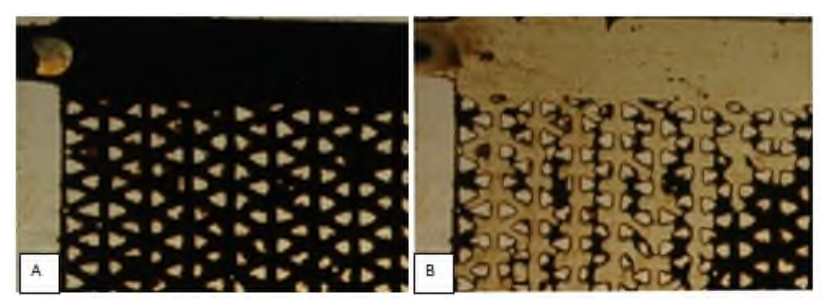

Fig.4: Wall A) oil saturated porous media before mud injection B)porous media after injection

\section{Conclusions}

Comparison between mud samples with and without nanoclay revealed that at high shear rates, adding nanoclay improved the reduction in viscosity by up to two times.

According to dynamic tests, the penetration depth of the formulation containing nanoclay and PAC (B5N0.75PAC )was about 1.5 times less than that of the base mud.

\section{Acknowledgement}

The authors would like to thank the IKIU nano-tech unit and micromodel laboratory of institute of petroleum Engineering of Tehran University for their financial and technical supports

\section{References}

[1] R.F.T. Lomba, A.L. Martins, C.M. Soares, E.M. Brandao, J.V.M. Magalhaes, M.V.D. Ferreira, Drill-in fluids: Identifying invasion mechanisms, Pap. SPE. 73714 (2002) 20-21.

[2] L. Skalli, J.S. Buckley, Y. Zhang, N.R. Morrow, Surface and core wetting effects of surfactants in oil-based drilling fluids, J. Pet. Sci. Eng. 52 (2006) 253-260. 
[3] F. Bergaya, G. Lagaly, General introduction: clays, clay minerals, and clay science, Dev. Clay Sci. 1 (2006) 1-18.

[4] R. Caenn, G. V Chillingar, Drilling fluids: State of the art, J. Pet. Sci. Eng. 14 (1996) 221230.

[5] K. Van Dyke, Drilling Fluids-Rotory Drilling Series Unit 2-Lessons 2, P ETEX. (2000).

[6] M.I. Abdou, H.-S. Ahmed, The compatibility of Egyptian bentonite during drilling shale formations, Pet. Sci. Technol. 29 (2011) 59-68.

[7] M.I. Abdou, H.E. Ahmaed, Evaluation of Low-solids Mud Reological Behavior during Drilling Shale Formation and Their Effect on the Pay Zone Productivity, Pet. Sci. Technol. 28 (2010) 934-945.

[8] M.I. Abdou, H. Abuseda, Improving the performance of clay from Gabal Um Qumar as drilling mud, Egypt. J. Pet. 23 (2014) 213-220.

[9] G. Brown, G.W. Brindley, Crystal structures of clay minerals and their X-ray identification, Mineral. Soc. London. (1980) 361-410.

[10] F. Bergaya, G. Lagaly, Handbook of clay science, Newnes, 2013.

[11] E. İşçi, S.İ. Turutoğlu, Stabilization of the mixture of bentonite and sepiolite as a water based drilling fluid, J. Pet. Sci. Eng. 76 (2011) 1-5.

[12] A.P.I.P. Dept, Recommended Practice Standard Procedure for Field Testing Water-based Drilling Fluids, American Petroleum Institute, 1990.

[13] W.A. Liao, Well servicing fluid for trenchless directional drilling, (1998).

[14] D. Gournis, C. Papachristodoulou, E. Maccallini, P. Rudolf, M.A. Karakassides, D.T. Karamanis, et al., A two-dimensional magnetic hybrid material based on intercalation of a cationic Prussian blue analog in montmorillonite nanoclay, J. Colloid Interface Sci. 348 (2010) 393-401. 